\title{
p38 MAP kinase inhibition enables proliferation of adult mammalian cardiomyocytes
}

\author{
Felix B. Engel, ${ }^{1}$ Michael Schebesta, ${ }^{1}$ Mychelle T. Duong, ${ }^{1}$ Gang Lu, ${ }^{2}$ Shuxun Ren, ${ }^{2}$ \\ Jeffery B. Madwed, ${ }^{3}$ Huiping Jiang, ${ }^{3}$ Yibin Wang, ${ }^{2}$ and Mark T. Keating ${ }^{1,4}$ \\ ${ }^{1}$ Howard Hughes Medical Institute, Department of Cell Biology, Harvard Medical School, Department of Cardiology, \\ Children's Hospital, Boston, Massachusetts 02115, USA; ${ }^{2}$ Molecular Biology Institute, Department of Anesthesiology \\ and Medicine, David Geffen School of Medicine, University of California, Los Angeles, California 90095, USA; \\ ${ }^{3}$ Department of Pharmacology, Boehringer Ingelheim Pharmaceuticals, Inc., Ridgefield, Connecticut 06410, USA
}

\begin{abstract}
Adult mammalian cardiomyocytes are considered terminally differentiated and incapable of proliferation. Consequently, acutely injured mammalian hearts do not regenerate, they scar. Here, we show that adult mammalian cardiomyocytes can divide. One important mechanism used by mammalian cardiomyocytes to control cell cycle is p38 MAP kinase activity. p38 regulates expression of genes required for mitosis in cardiomyocytes, including cyclin A and cyclin B. p38 activity is inversely correlated with cardiac growth during development, and its overexpression blocks fetal cardiomyocyte proliferation. Activation of p38 in vivo by MKK3bE reduces BrdU incorporation in fetal cardiomyocytes by $17.6 \%$. In contrast, cardiac-specific $p 38 \alpha$ knockout mice show a $\mathbf{9 2 . 3 \%}$ increase in neonatal cardiomyocyte mitoses. Furthermore, inhibition of p38 in adult cardiomyocytes promotes cytokinesis. Finally, mitosis in adult cardiomyocytes is associated with transient dedifferentiation of the contractile apparatus. Our findings establish p38 as a key negative regulator of cardiomyocyte proliferation and indicate that adult cardiomyocytes can divide.
\end{abstract}

[Keywords: p38 MAP kinase; cytokinesis; cardiomyocytes; dedifferentiation; regeneration; proliferation]

Supplemental material is available at http://www.genesdev.org.

Received February 15, 2005; revised version accepted April 4, 2005.

Highly differentiated mammalian cells are thought to be incapable of proliferation. These cells have exited the cell cycle. Proteins critical for cellular specialization have accumulated and driven these cells to their final form and function (Studzinski and Harrison 1999). In contrast with mammals, differentiated cells in teleost fish (Poss et al. 2002, 2003) and urodele amphibians (Brockes and Kumar 2002) can dedifferentiate and/or proliferate, enabling regeneration. For example, zebrafish hearts regenerate through cardiomyocyte proliferation (Poss et al. 2002). Thus, a thorough understanding of mechanisms regulating cell cycle exit, and the development of approaches to reactivate proliferation of mammalian cells, will be of great therapeutic value.

Mammalian cardiac regeneration has been studied since the mid-nineteenth century. The consistent conclusion of these studies has been that the heart has little or no regenerative capacity (Rumyantsev 1977; Mummery 2005). This is a major medical problem, as is-

${ }^{4}$ Corresponding author.

E-MAIL mkeating@enders.tch.harvard.edu; FAX (617) 730-8317. Article published online ahead of print. Article and publication date are at http://www.genesdev.org/cgi/doi/10.1101/gad.1306705. chaemic heart disease, resulting in cardiac muscle loss, is the leading cause of morbidity and mortality in the industrialized world. Here, we have studied the proliferation potential of adult mammalian cardiomyocytes.

In contrast to adult cardiomyocytes, mammalian cardiomyocytes do proliferate during fetal development. Shortly after birth, these cardiomyocytes down-regulate cell-cycle-perpetuating factors like cyclin A and cdk2. The loss of proliferation capacity coincides with increased levels of the cell cycle inhibitors p21 and p27 (Pasumarthi and Field 2002). At this point of development, post-natal cardiac growth is mediated by cardiomyocyte hypertrophy. This transition from hyperplastic to hypertrophic growth is characterized by maturation of the contractile apparatus, a cytoplasmic structure that is thought to preclude cytokinesis (Rumyantsev 1977). Thus, primary adult mammalian cardiomyocytes are thought to be incapable of cytokinesis.

In general, there is an inverse relationship between proliferation and differentiation (Studzinski and Harrison 1999), and molecules that promote differentiation may also repress cell cycle re-entry. It has been shown that the signaling molecule p38 mitogen-activated protein (MAP) kinase (p38) induces cell cycle exit and dif- 
Engel et al.

ferentiation of many cell types (Nebreda and Porras 2000; Wu et al. 2000; Ambrosino and Nebreda 2001; Bulavin et al. 2002; Shi and Gaestel 2002), including differentiation of P19 cells to cardiomyocytes (Eriksson and Leppa 2002). Activated p38 phosphorylates downstream signaling molecules important for cardiomyocyte differentiation and hypertrophy (Liang and Molkentin 2003). Four different p38 isoforms have been identified. The main isoform expressed in the heart is p38 $\alpha$. p38 $\beta$ and p38 $\gamma$ are expressed at low levels, and p38 is not expressed in heart (Wang et al. 1997; Liao et al. 2001; Liang and Molkentin 2003). Previously, it was not known if the effects of p38 on differentiation and proliferation are reversible.

Here, we show that post-mitotic mammalian cardiomyocytes can proliferate. One mechanism of cell cycle regulation for mammalian cardiomyocytes is p38 activity; that is, p38 is a key negative regulator of mammalian cardiomyocyte division. p38 activity is inversely correlated with cardiac growth during development, and its overexpression blocks proliferation of fetal cardiomyo- cytes in vitro. Genetic activation of p38 in vivo reduces fetal cardiomyocyte proliferation, whereas targeted disruption of $p 38 \alpha$ increases neonatal cardiomyocyte mitoses. Furthermore, we demonstrate that growth factor stimulation and p38 inhibition induce cytokinesis in adult cardiomyocytes. These results indicate that the inhibitory effects of p38 on cardiomyocyte proliferation are reversible and that post-mitotic, differentiated cells are capable of proliferation.

\section{Results}

\section{p38 inhibition regulates genes critical for mitosis in cardiomyocytes}

To determine the effect of p38 inhibition on cardiomyocyte differentiation and proliferation, we used a specific inhibitor of p38 $\alpha$ and p38 $\beta$, SB203580, and performed cDNA microarray analyses using neonatal rat cardiomyocytes (Fig. 1A). Known genes that were consistently up- or down-regulated twofold or more by p38 inhibition
Figure 1. p38 regulates genes critical for mitosis in neonatal rat cardiomyocytes. Gene expression in neonatal cardiomyocytes was determined using microarray, RT-PCR, and immunofluorescence analyses. (A) Genes consistently up- or downregulated twofold or more by treatment with FGF1 and p38 inhibitor SB203580 (p38i), alone or in combination, after $72 \mathrm{~h}$ were grouped into functional classes and clustered by response. (B) RT-PCR analyses (in duplicate) of selected genes validated that inhibition of p38 alone increases expression of cell cycle regulators including cyclin A2, cdc2a, and cyclin B. p38 inhibition also down-regulated genes like Seta/Ruk, an inhibitor of PI3 kinase. (C) Treatment with FGF1 + p38i, but not FGF1 alone, induced dramatic changes in cyclin A, Ki67, phospho-Rb, cdc2, and p27 protein levels $(n=3$, mean $\pm \mathrm{SD})$. (D) Cardiomyocytes stained for tropomyosin (red) and DAPI (blue) show increased cyclin A, cdc2, phospho-Rb, and Ki67 protein expression (green) after stimulation with FGF1 + p38i. (E) Cardiomyocytes stained for troponin I (red) had decreased expression of the cell cycle inhibitor p27 (green) after FGF1 + p38i treatment.

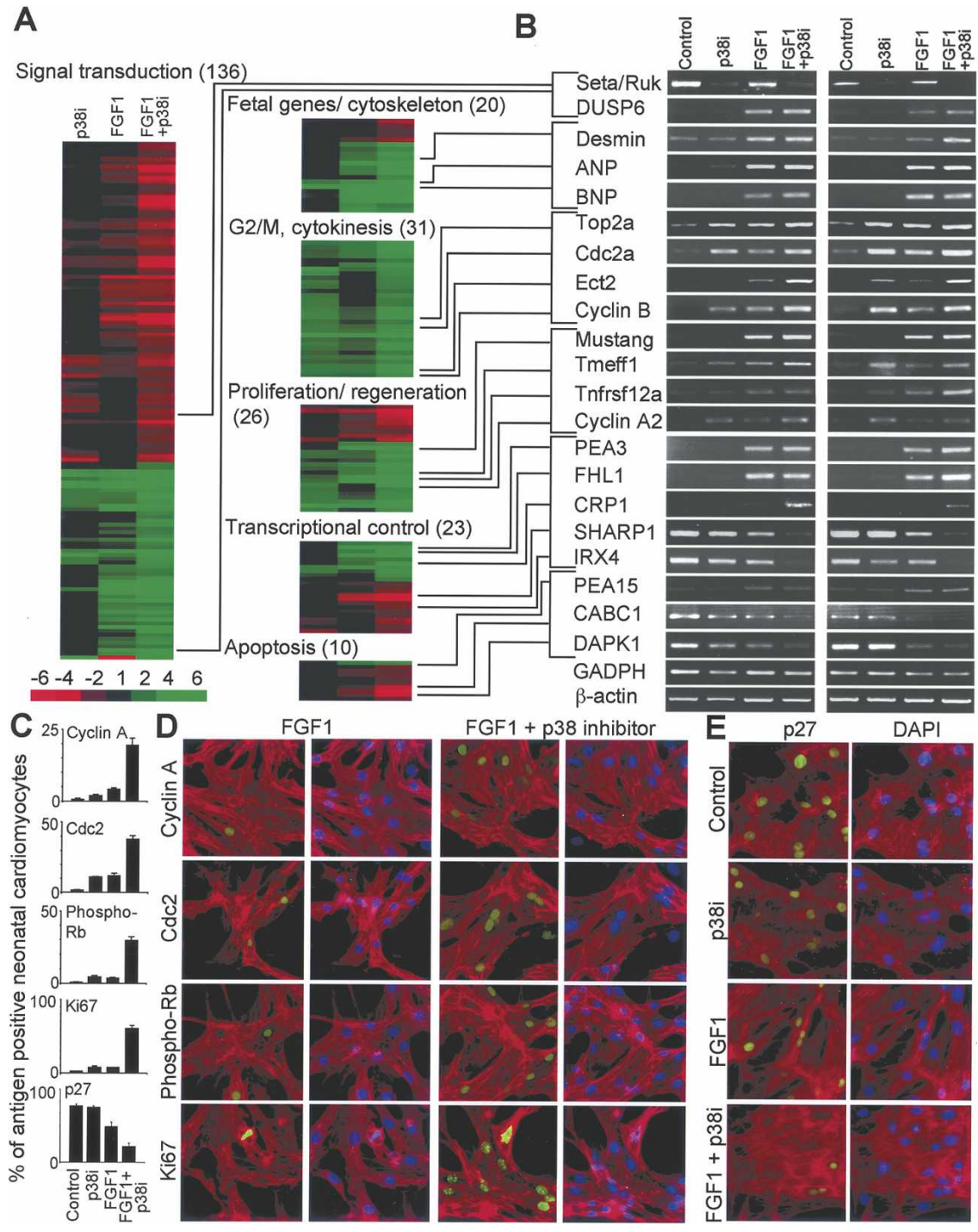


after $72 \mathrm{~h}$ were grouped into functional classes and clustered by response (Fig. 1A; Supplementary Table S1). We validated expression changes of a subset of genes by RTPCR (Fig. 1B).

Down-regulation of cyclin A is an early sign of cell cycle exit in mammalian cardiomyocytes (Yoshizumi et al. 1995). In addition, it has been shown that cardiacspecific overexpression of cyclin A2 from embryonic day 8 into adulthood increases cardiomyocyte mitosis during post-natal development (Chaudhry et al. 2004). We discovered that p38 inhibition up-regulated cyclin A2 (Fig. 1B). p38 inhibition also regulated other genes involved in mitosis and cytokinesis, including cyclin B, cdc2, and aurora B (Wheatley et al. 2001; Murray 2004). We expected that these changes might also be associated with evidence of dedifferentiation, such as induction of fetal genes. However, we observed only a slight induction of ANP. Thus, p38 activity regulates genes important for mitosis in cardiomyocytes.

Stimulation of neonatal cardiomyocytes with FGF1 induces fetal gene expression (Parker et al. 1990). To determine if FGF1, in combination with p38 inhibition, can reverse differentiation and induce cell cycle re-entry, we repeated cDNA microarray analyses (Fig. 1A,B; Supplementary Table S1). FGF1 up-regulated genes that are associated with fetal cardiac development, including ANP and BNP (Cameron and Ellmers 2003), and the Ets-related transcription factor PEA3 (ChotteauLelievre et al. 1997). In addition, FGF1 up-regulated genes previously implicated in regeneration and cell cycle control, including Mustang (Lombardo et al. 2004). Finally, FGF1 down-regulated pro-apoptotic genes, like CABC1 (Iiizumi et al. 2002), and up-regulated anti-apoptotic genes, like PEA15 (Kitsberg et al. 1999). Taken together, these data suggest that FGF1 induces partial dedifferentiation and possibly protects cardiomyocytes from apoptosis.

Expression analysis revealed that p38 inhibition and FGF1 together modulate expression of specific genes, whereas p38 inhibition or FGF1 stimulation alone had little or no effect. For example, p38 inhibition and FGF1 dramatically modulated expression of the cytokinesis regulator Ect2 (Saito et al. 2004), the bHLH factor SHARP1 (Azmi et al. 2003), the cell-cycle-regulated protein CRP1 (Weiskirchen et al. 1995), and the mediator of ventricular cardiomyocyte differentiation, IRX4 (Fig. 1B; Bao et al. 1999). For a subset of cell-cycle-perpetuating factors, including Ki67, cdc2, and cyclin A, and the cell cycle inhibitor $\mathrm{p} 27$, the combined effect of $\mathrm{p} 38$ inhibition and FGF1 stimulation was even greater at the protein level (Fig. 1C-E). The proliferation marker Ki67 (Brown and Gatter 2002), for example, was increased sevenfold. Finally, p38 inhibitor and FGF1, but neither factor alone, led to phosphorylation of $\mathrm{Rb}$, a key cell cycle regulator (Fig. 1C,D; Classon and Harlow 2002). Taken together, our data indicate that p38 inhibition and FGF1 stimulation act synergistically to induce expression of genes involved in proliferation and regeneration. p38 activity blocks fetal cardiomyocyte proliferation

Fetal cardiomyocytes proliferate during development but lose this capacity shortly after birth. The switch from proliferative to hypertrophic growth has been associated with up- and down-regulation of many factors. However, its mechanism is not understood. To determine if p38 regulates fetal cardiomyocyte proliferation, we examined prenatal cardiac growth. We collected rat hearts at sequential developmental stages (embryonic days 12-21 [E12-E21], post-natal day 2 [P2], and adult), and assessed the cardiac growth rate ( $n=18-40$ per time point) and p38 activity ( $n=5$ litters) (Fig. $2 \mathrm{~A}-\mathrm{C})$. Cardiac growth rate mediated predominantly by fetal cardiomyocyte proliferation (Rumyantsev 1977; Pasumarthi and Field 2002) was defined as the percentage increase of maximal ventricular area (Fig. 2A). The rate of cardiac growth decreased sharply from E13 to E15 $(p<0.01)$, accelerated from E17 to E19 $(p<0.01)$, and decreased again (Fig. 2B). p38 activity, in contrast, was inversely correlated with cardiac growth (Fig. 2B,C). p38 activity was low at E12, peaked at E15, declined to a second low at E19, rose again, and stayed high in adults $(p<0.01)$. At E13, for example, cardiac area doubled and p38 activity was low (4.51). In contrast, at E15, cardiac area increased only $35 \%$ and p38 activity was high (11.89). These data indicate an association between p38 activity and fetal cardiomyocyte proliferation.

To directly assess the role of p38 in regulating fetal cardiomyocyte proliferation, we overexpressed GFP, $\mathrm{p} 38 \alpha$, and a dominant-negative form of $\mathrm{p} 38 \alpha(\mathrm{p} 38 \alpha \mathrm{DN})$ in fetal (E19) cardiomyocytes. p38 $\alpha \mathrm{DN}$ is mutated in its dual phosphorylation site, causing lack of kinase activity (Raingeaud et al. 1995). Cells were electroporated, cultured for $36 \mathrm{~h}$, and stimulated for $24 \mathrm{~h}$ with FGF1 in the presence of BrdU (5-bromo-2'-deoxyuridine), a marker of DNA synthesis. The rate of BrdU incorporation in mocktransfected cells (GFP) was $23 \% \pm 5.2 \%$. Overexpression of $\mathrm{p} 38 \alpha(3.4 \% \pm 1.9 \%)$, but not p38 $\mathrm{DNN}(19.2 \% \pm 4.8 \%)$, decreased FGF1-induced BrdU incorporation significantly (Fig. 2D,E). As shown in Figure 2C, p38 activity is very low in the fetal heart at this stage of development, thus overexpression of $\mathrm{p} 38 \alpha \mathrm{DN}$ was not expected to have a significant effect. These results indicate that $\mathrm{p} 38 \alpha$ is a potent regulator of fetal cardiomyocyte proliferation in vitro.

To determine the role of p38 activation in vivo, we examined transgenic animals with cardiomyocyte-specific expression of a constitutively active upstream kinase for $\mathrm{p} 38, \mathrm{MKK} 3 \mathrm{bE}$. Targeted activation of $\mathrm{p} 38$ in ventricular myocytes was achieved in vivo by using a geneswitch transgenic strategy resulting in the expression of MKK3bE mutant protein under the control of the $\alpha$ MHC promoter (Liao et al. 2001). Previously, it has been demonstrated that activation of p38 kinase activity causes a thin ventricular wall (Liao et al. 2001). The underlying mechanism of this phenotype is unclear, but induction of apoptosis was excluded. As shown in Figure $2 \mathrm{~F}, \mathrm{BrdU}$ incorporation in fetal cardiomyocytes (E21) was reduced from $18.2 \% \pm 3.4 \%$ to $15.0 \% \pm 2.9 \%$ in 
Engel et al.

Figure 2. p38 controls fetal cardiomyocyte proliferation in vitro and in vivo. $(A)$ Rat hearts grew rapidly during embryonic development. $(B)$ The rate of cardiac growth (black line) was inversely correlated with p38 activity (orange bars, $n=5$, mean \pm SD). p38 activity was measured by its ability to phosphorylate ATF-2. p38 activity was biphasic during development, low at E12 and E19, and high at E15 and E21-adult. $(C)$ Western analysis showed biphasic p38 activity, while p38 protein levels were constant. $(D, E)$ Overexpression of wild-type p38 $(D)$, but not dominant-negative $\mathrm{p} 38 \alpha(\mathrm{p} 38 \alpha \mathrm{DN})(E)$, blocked BrdU incorporation in fetal cardiomyocytes $(n=3$, mean $\pm \mathrm{SD}, p<0.05)$. Fetal cardiomyocytes stained for Nkx2.5 (red), BrdU (green), and Flagtagged $\mathrm{p} 38 \alpha$ or $\mathrm{p} 38 \alpha \mathrm{DN}$ (blue). Arrowheads indicate BrdU-positive cardiomyocytes expressing p $38 \alpha \mathrm{DN}$. $(F)$ Quantitative analysis of BrdU incorporation in fetal cardiomyocytes (MEF2-positive, E21) of $M K K 3 b E$ transgenic $\left(M K K 3 b E^{+}\right)$and nontransgenic $\left(M K K 3 b E^{-}\right)$ littermates in vivo. Note that BrdU incorporation in cardiomyocytes of $M K K 3 b E$ transgenic mice decreased from $18.2 \% \pm 3.4 \%$ to $15.0 \% \pm 2.9 \%$ (mean $\pm \mathrm{SD}, 17.6 \%$ reduction, $p<0.05)$. Mean is indicated by a red line.
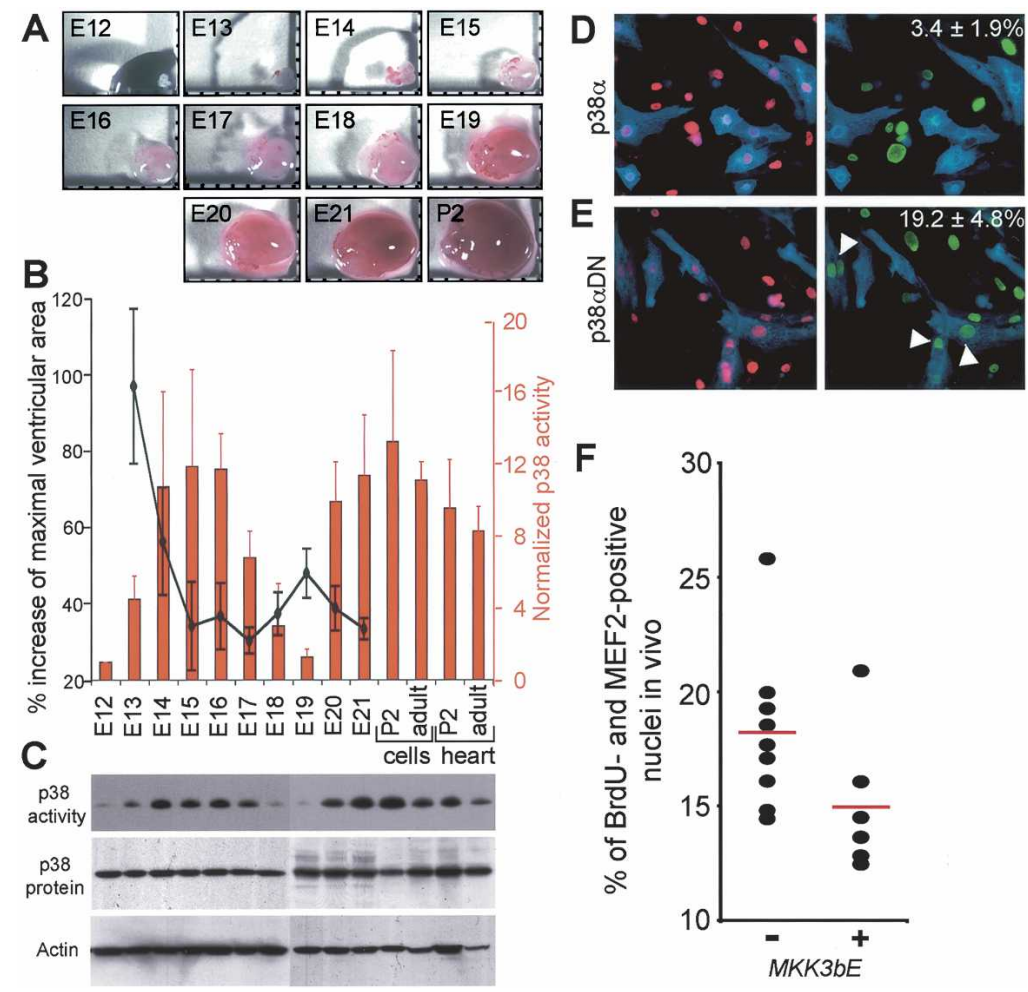

MKK3bE transgenic hearts. This is a reduction of $17.6 \%$ $(p<0.05)$ in cardiomyocyte proliferation. Taken together, our results indicate that p38 activity is a potent negative regulator of fetal cardiomyocyte proliferation in vitro and in vivo.

\section{p38a inhibition promotes neonatal cardiomyocyte proliferation in vitro}

Several growth factors have a limited capacity to induce DNA synthesis in neonatal cardiomyocytes, including FGF1 (Pasumarthi and Field 2002). We screened 45 extracellular factors at two different concentrations for their ability to induce BrdU incorporation in neonatal (P2) cardiomyocytes. Cells were stimulated every $24 \mathrm{~h}$ for $3 \mathrm{~d}$ and pulse-labeled with BrdU for the final $24 \mathrm{~h}$. We confirmed previous studies showing that FGF1, IL-1 $\beta$, and NRG-1- $\beta 1$ are potent growth factors for neonatal cardiomyocytes (Fig. 3A,B; Supplementary Table S2; Pasumarthi and Field 2002).

Inhibition of p38 activity by SB203580 increased BrdU incorporation 2.8-fold in neonatal cardiomyocytes stimulated with FGF1 $(p<0.01)$ (Fig. 3A,B). Similar results were obtained after stimulation with IL-1 $\beta$ and NRG-1- $\beta 1$. Thus, inhibition of p38 activity augments growth factor-mediated DNA synthesis in neonatal cardiomyocytes.

To support the specificity of SB203580, we repeated these experiments with dominant-negative forms of $\mathrm{p} 38 \alpha(\mathrm{p} 38 \alpha \mathrm{DN})$ and $\mathrm{p} 38 \beta(\mathrm{p} 38 \beta \mathrm{DN})$. Adenovirus-mediated expression of $\mathrm{p} 38 \alpha \mathrm{DN}$ was as effective as SB203580 in increasing growth-factor-mediated BrdU incorpora- tion (Fig. 3C). In contrast, expression of p38 $\beta D N$ had no effect on DNA synthesis. These results are consistent with previous findings showing that $\mathrm{p} 38 \alpha$ and $\mathrm{p} 38 \beta$ have distinct downstream targets (Enslen et al. 1998; Wang et al. 1998). Taken together, our data indicate that the effect of p38 on DNA synthesis in neonatal cardiomyocytes is mediated by $\mathrm{p} 38 \alpha$.

To determine if $\mathrm{p} 38$ also regulates karyokinesis in neonatal cardiomyocytes, we assayed mitosis by immunofluorescence staining of phosphorylated histone-3 (H3P). Inhibition of p38 activity using SB203580 increased the number of H3P-positive cells 3.9-fold in the presence of FGF1 + NRG-1- $\beta 1$, resulting in $5.4 \% \pm 0.8 \%$ H3P-positive cardiomyocytes $(p<0.01)$ (Fig. 3D,E). This value is comparable to that of proliferating cell lines and the mitotic index of fetal cardiomyocytes during embryonic development $(E 12,3.7 \% \pm 0.6 \%)$ (data not shown). Thus, p38 activity regulates neonatal cardiomyocyte karyokinesis.

During post-natal development, mammalian cardiomyocytes frequently undergo karyokinesis without cytokinesis, and $\sim 60 \%$ of human, and $85 \%$ of rat, adult cardiomyocytes are binucleated (Brodsky 1991). To test if p38 regulates cell division in neonatal cardiomyocytes, we performed cell count experiments. The percentage of cardiomyocytes was determined by tropomyosin staining and FACS analyses. Cells were incubated with SB203580 and stimulated once with growth factors on day 0. As shown in Figure 4A, this resulted in significantly increased cell numbers (day 3: $p<0.05$; days 4 and 5: $p<0.01)$. The maximal increase in cardiomyocyte number of 2.6-fold was seen with FGF1 + IL-1 $\beta$ stimula- 
A
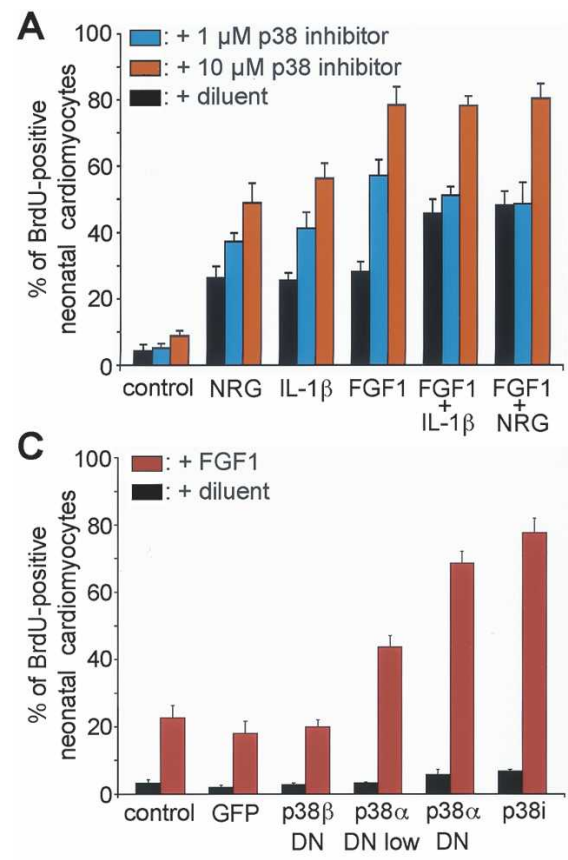

D

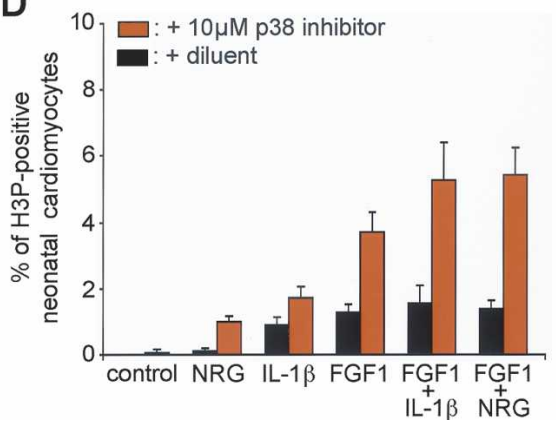

B

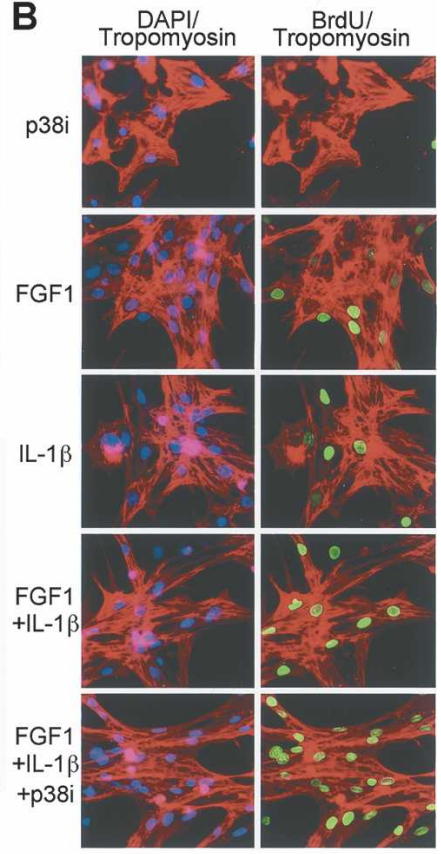

E

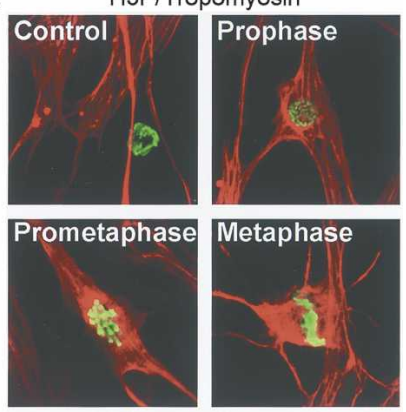

Figure 3. p38 $\alpha$ regulates neonatal cardiomyocyte proliferation potential. Neonatal rat cardiomyocytes were stimulated with FGF1, IL-1 $\beta$, and/or NRG-1$\beta 1$ with or without $\mathrm{p} 38$ inhibition, and analyzed for DNA synthesis (BrdU) or karyokinesis (H3P). (A) p38i increased growth-factor-induced DNA synthesis. Note that $80.4 \% \pm 4.4 \%$ of cardiomyocytes were BrdU-positive after stimulation with FGF1, NRG-1$\beta 1$ (NRG), and $10 \mu \mathrm{M}$ p38i $(n=3$, mean \pm SD, $p<0.01)$. The diluent for p38i was DMSO. $(B)$ Examples of cardiomyocytes stained for tropomyosin (red), BrdU (green), and DAPI (blue) used for quantitative analyses in $A$. $(C)$ Dominant-negative (inhibition of $\mathrm{p} 38 \alpha$, but not $\mathrm{p} 38 \beta$, increased FGF1-induced BrdU incorporation $(p<0.01)(\mathrm{DN})$ Adenoviral infection with dominant-negative constructs; (low) 100 $\mathrm{PFU} /$ cell, high is $500 \mathrm{PFU} /$ cell. The diluent for FGF1 was $0.1 \%$ BSA/PBS. $(D)$ p38 inhibition significantly increased growth-factor-induced karyokinesis $(n=3$, mean $\pm \mathrm{SD}, p<0.01)$. (E) Neonatal cardiomyocytes undergoing karyokinesis following FGF1 + p38i treatment (tropomyosin: red, H3P: green). tion at day 5 . There was no evidence of binucleation by FACS analysis (data not shown).

To determine if neonatal cardiomyocytes can divide more than once, we stimulated cardiomyocytes continuously with FGF1 in the presence of SB203580 and monitored cell proliferation. The number of cardiomyocytes continued to increase until cells reached confluence (Fig. 4B). This indicates multiple rounds of cardiomyocyte division. BrdU and $\mathrm{H} 3 \mathrm{P}$ analyses further supported that cardiomyocyte proliferation continued until cells became confluent (Fig. 4C). Thus, cardiomyocytes in the presence of p38 inhibition and growth factor stimulation continue to proliferate until mitosis is abrogated by contact inhibition.

To confirm that p38 inhibition promotes cardiomyocyte cell division, we assayed cytokinesis using immunofluorescence staining with aurora B or survivin antibodies. Aurora B kinases form a complex with inner centromere protein and survivin. Both proteins associate with centromeric heterochromatin early in mitosis, transfer to the central spindle, and finally localize to the contractile ring and midbody (Wheatley et al. 2001). Thus, aurora B and survivin are markers of cytokinesis. Aurora B and survivin assays confirmed that p38 inhibi- tion and growth factor stimulation induced neonatal cardiomyocyte cytokinesis in vitro (Fig. 4D).

\section{Increased cardiomyocyte mitosis in p38 $\alpha$ knockout mice}

To determine if proliferation of neonatal cardiomyocytes can be modulated by p38 $\alpha$ inhibition in vivo, we examined mice in which p38 $\alpha$ activity was disrupted specifically in cardiomyocytes. The conditional knockout $\left(p 38 \alpha^{\Delta / \Delta}\right)$ was achieved by crossing homozygous floxed p38 $\alpha$ mice $\left(p 38^{\operatorname{lox} P / \operatorname{lox} P}\right)$ (Fig. 5A) with a cardiomyocytespecific cre line (MLC-2a/Cre). Western analyses indicated a dramatic reduction $(>90 \%)$ of p38 $\alpha$ protein specifically in cardiomyocytes (Fig. 5B,C). p38 $\beta$ and p38 $\gamma$ protein levels were unaffected (Fig. 5D). Cardiac-specific deletion of $p 38 \alpha$ diminished $\mathrm{p} 38 \alpha$ downstream signaling (MAPKAPK2) but did not affect ERK phosphorylation (Fig. 5E).

To analyze the effect of $\mathrm{p} 38 \alpha$ inactivation on the cell cycle in neonatal cardiomyocytes in vivo, we assayed BrdU and $\mathrm{H} 3 \mathrm{P}$ in $p 38 \alpha^{\Delta / \Delta}$ mice. Among littermates, BrdU incorporation was highest in $p 38 \alpha^{\Delta / \Delta}$ mice. As shown in Figure 5F and G, BrdU incorporation in neonatal 
Engel et al.

Figure 4. p38 controls neonatal cardiomyocyte proliferation. Neonatal cardiomyocyte proliferation was analyzed by cell count, FACS, BrdU, $\mathrm{H} 3 \mathrm{P}$, survivin, and aurora B staining. $(A)$ p38 inhibition augmented growth-factor-induced cardiomyocyte proliferation as measured by cell count $(n=2$ or 3 for each time point, mean $\pm \mathrm{SD}$; day 3: $p<0.05$, days 4 and 5: $p<0.01)$. Note that a single stimulation with FGF1 and IL- $1 \beta$ in the presence of p38i increased cardiomyocyte numbers by 2.6 -fold after $5 \mathrm{~d}$ of stimulation. (B) Cardiomyocytes were seeded in a labeled microtiter well, continuously stimulated with FGF1 (day 0, day 3, day 6) in the presence of p38i, and analyzed over time. (C) Continuous stimulation with FGF1 in the presence of p38i resulted in BrdU incorporation and $\mathrm{H} 3$ phosphorylation until cells reached confluence at day 8 , suggesting proliferation. (D) Neonatal cardiomyocytes undergoing cytokinesis in response to FGF1 + p38i. The contractile ring and midbody of dividing cells were stained with survivin or aurora B (green). Cardiomyocytes were identified by tropomyosin or troponin $\mathrm{T}$ (red). Controls show dividing nonmyocytes.
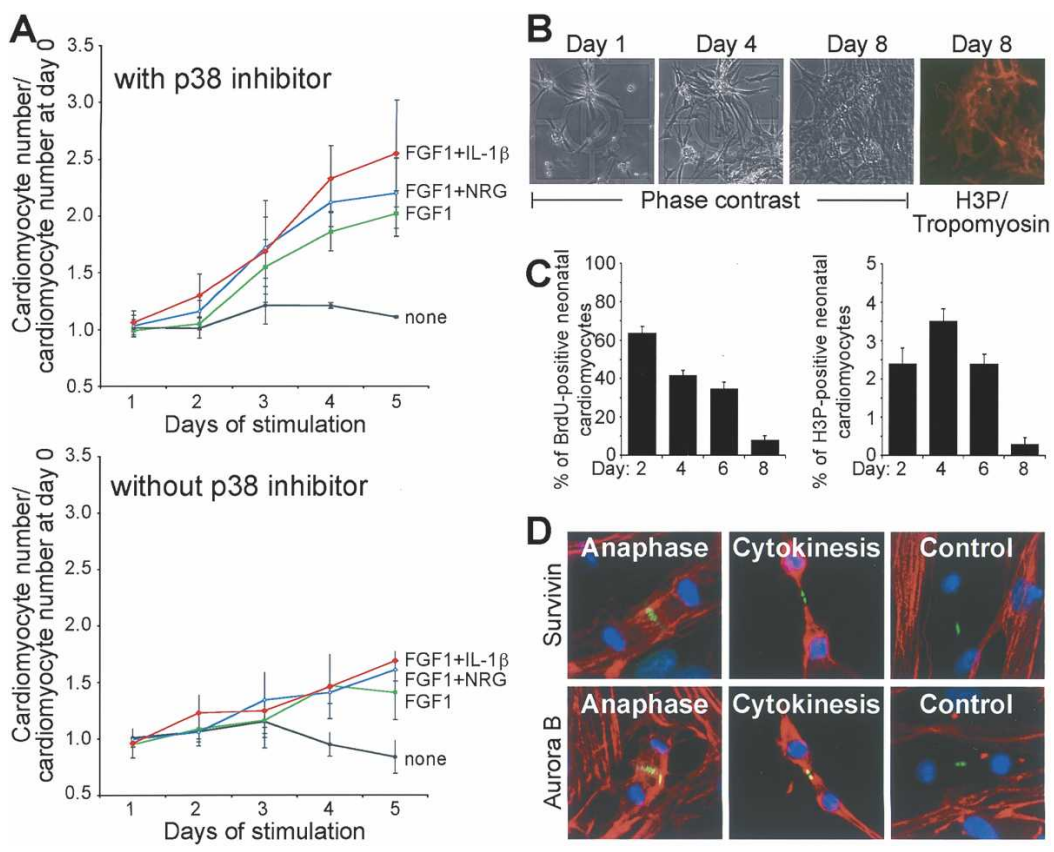

cardiomyocytes (P4) was increased from $14.2 \% \pm 2.0 \%$ to $17.2 \% \pm 3.1 \%(17.2 \%$ increase, $p<0.05)$. These data indicate that reduced $\mathrm{p} 38 \alpha$ protein causes increased cardiomyocyte DNA synthesis in vivo. $\mathrm{H} 3$ phosphorylation was increased from $0.13 \% \pm 0.05 \%$ to $0.25 \% \pm 0.07 \%$ $(92.3 \%$ increase, $p<0.01)$, indicating that reduced $\mathrm{p} 38 \alpha$ protein resulted in increased mitosis in cardiomyocytes in vivo (Fig. $5 \mathrm{H}, \mathrm{I}$ ).

Furthermore, we examined the effects of $\mathrm{p} 38 \alpha$ protein reduction on BrdU incorporation in adult cardiomyocytes. To distinguish between adult cardiomyocytes and interstitial cells, hearts were sectioned and stained for the cardiac transcription factor GATA4 and a marker for cell membranes, Caveolin (Fig. 5J,K). We detected BrdUpositive adult cardiomyocytes in vivo. The number of BrdU-positive cardiomyocytes per longitudinal section in $p 38 \alpha^{\Delta / \Delta}$ mice $(1.7 \pm 0.4)$ was 20 -fold greater than observed in $p 38^{\text {loxP/loxP }}$ mice $(0.08 \pm 0)$. Taken together, our data indicate that $\mathrm{p} 38 \alpha$ is a negative regulator of cardiomyocyte proliferation in vivo.

\section{Adult cardiomyocytes divide}

In contrast to neonatal cardiomyocytes, previous studies indicate that no DNA synthesis, karyokinesis, or cytokinesis occurs in rat cardiomyocytes $3 \mathrm{wk}$ after birth (Rumyantsev 1977; Pasumarthi and Field 2002). To determine if p38 inhibition promotes growth-factormediated DNA synthesis in adult cardiomyocytes, we repeated cell proliferation assays using ventricular cardiomyocytes from 12-wk-old rats. As an additional cardiomyocyte-specific marker, we used the transcription factor Nkx2.5. Cardiomyocytes were isolated at day 0 , and allowed to recover for $24 \mathrm{~h}$. Cells were then stimulated every $3 \mathrm{~d}$ with growth factors in the presence or absence of SB203580 for $12 \mathrm{~d}$ and assayed for BrdU. FGF1 alone and FGF1 + IL-1 $\beta$ induced BrdU incorporation in $>2 \%$ of adult cardiomyocytes. Inhibition of p38 doubled the effect of growth factors $(p<0.01)$ (Fig. 6A). These data demonstrate that p38 inhibition promotes growthfactor-induced DNA synthesis in adult cardiomyocytes.

To determine if adult cardiomyocytes can undergo karyokinesis, we performed $\mathrm{H} 3 \mathrm{P}$ analyses. Inhibition of p38 activity increased the number of H3P-positive cardiomyocytes 3.7-fold in the presence of FGF1 $(p<0.01)$ (Fig. 6B,D). These findings indicate that p38 regulates karyokinesis of adult cardiomyocytes.

To learn if adult mammalian cardiomyocytes can undergo cytokinesis, we assayed aurora B. Inhibition of p38 increased cytokinesis 3.8-fold $(p<0.01)$ (Fig. 6C). The maximum effect was observed with p38 inhibition and FGF1. Although most proliferating adult cardiomyocytes were mononucleated (Fig. 6E,D), we also observed binucleated cells undergoing cytokinesis (Fig. 6G,H). These data indicate that adult ventricular cardiomyocytes can divide.

To estimate how many cardiomyocytes proliferate after $12 \mathrm{~d}$ of stimulation, we repeated these experiments using Ki67 (Brown and Gatter 2002). In neonatal cardiomyocytes, FGF1 induced DNA synthesis, but failed to induce proliferation and Ki67 expression (Fig. 1C,D). In contrast, FGF1 stimulation in the presence of SB203580 resulted in both cardiomyocyte proliferation and $\mathrm{Ki} 67$ expression. Thus, Ki67 is an excellent marker for cardiomyocyte proliferation. In adult cardiomyocytes, stimulation with FGF1 alone resulted in $1.7 \% \pm 0.5 \% \mathrm{Ki} 67$ positive cells (data not shown). However, stimulation with FGF1 and p38 inhibitor resulted in $7.2 \% \pm 1.2 \%$ Ki67-positive adult cardiomyocytes $(p<0.01)$. Taken together, these data indicate that adult cardiomyocytes can proliferate in vitro, and that p38 potently controls this process. 


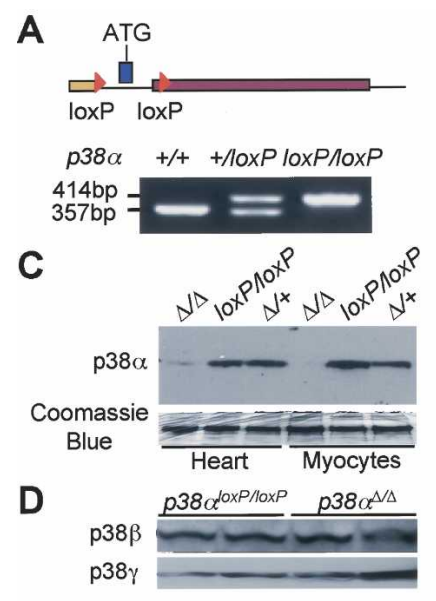

B
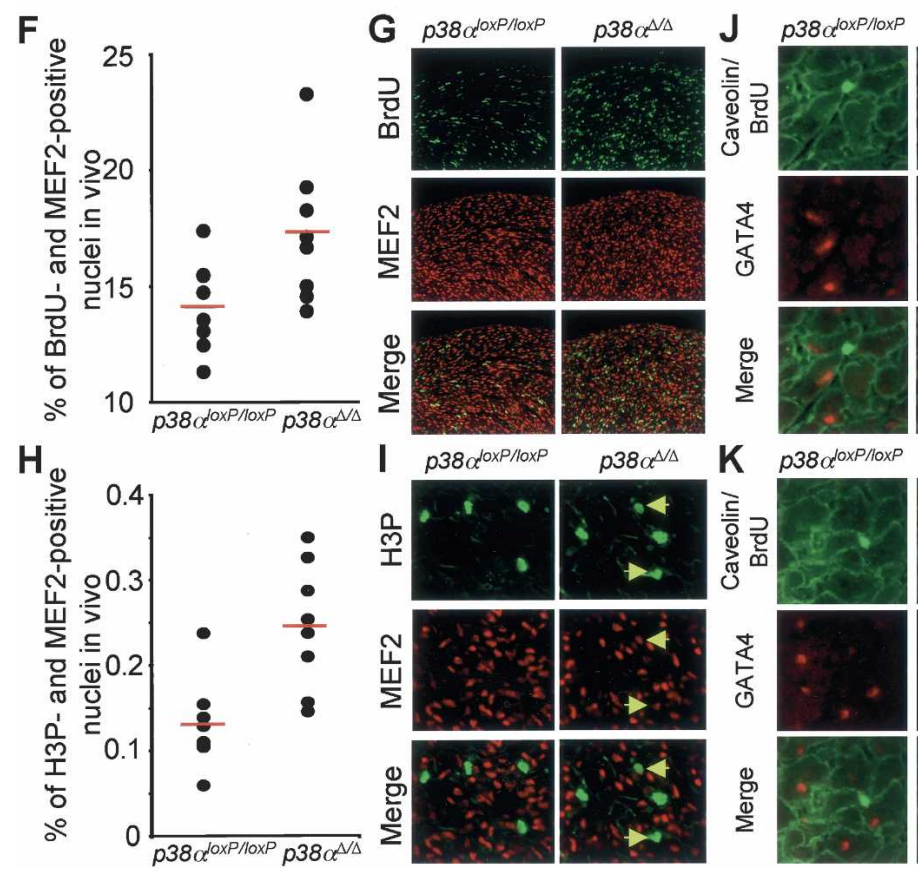

Figure 5. $p 38 \alpha$ knockout shows increased neonatal cardiomyocyte mitosis in vivo. BrdU and $\mathrm{H} 3 \mathrm{P}$ analyses in cardiac-specific $p 38 \alpha$ knockout mice $\left(p 38 \alpha^{\Delta / \Delta}\right)$ and littermates $\left(p 38 \alpha^{\text {loxp/loxP }}\right) .(A)$ Schematic structure of floxed allele of $p 38 \alpha$ gene and PCR results of wild-type, heterozygous, and homozygous mice. $(B, C)$ The Western blot shows p38 $\alpha$ expression was unaffected in noncardiac tissues of $p 38 \alpha^{\Delta / \Delta}$ animals. In contrast, p38 $\alpha$ expression in whole heart and isolated adult ventricular myocytes of $p 38 \alpha^{\Delta / \Delta}$ was dramatically down-regulated compared to $p 38 \alpha^{\operatorname{lox} P / \operatorname{lox} P}$ and heterozygous $p 38 \alpha$ knockout mice $\left(p 38 \alpha^{\Delta /+}\right)$. $(D)$ Western blot demonstrating unaltered p $38 \beta$ and p38 $\gamma$ expression in $p 38 \alpha^{\Delta / \Delta}$ hearts. $(E)$ Cardiacspecific deletion of $p 38 \alpha$ diminished $\mathrm{p} 38 \alpha$ downstream signaling (MAPKAPK2) but did not affect ERK phosphorylation. (F) DNA synthesis (BrdU) increased in $p 38 \alpha^{\Delta / \Delta}$ neonatal cardiomyocytes from $14.2 \% \pm 2.0 \%$ to $17.24 \% \pm 3.1 \%$ (the red line is mean $\pm \mathrm{SD}, 17.2 \%$ increase, $p<0.05) .(G)$ Examples of hearts stained for MEF2 (red) and BrdU (green) used for quantitative analyses in $F$. $(H)$ Mitotic activity $(\mathrm{H} 3 \mathrm{P})$ increased from $0.13 \% \pm 0.05 \%$ to $0.25 \% \pm 0.07 \%$ in hearts of p38 $\alpha^{\Delta / \Delta}$ mice (the red line is mean $\pm \mathrm{SD}, 92.3 \%$ increase, $p<0.01)$. (I) Examples of hearts stained for MEF2 (red) and H3P (green) used for quantitative analyses in $H$. Arrows indicate H3P-positive neonatal cardiomyocyte nuclei. $(J, K)$ Adult heart sections showing $p 38^{\operatorname{lox} P / / 0 x P}$ and $p 38 \alpha^{\Delta / \Delta}$ cardiomyocytes stained for GATA4 (red), BrdU, and Caveolin (both green). These data indicate that $\mathrm{p} 38 \alpha$ regulates cardiomyocyte proliferation in vivo.

\section{Sarcomeres dedifferentiate during cardiomyocyte proliferation}

Fetal cardiomyocytes transiently dedifferentiate during mitosis in vivo (Rumyantsev 1977). To learn if growth factor stimulation and p38 inhibition induce sarcomeric dedifferentiation in adult cardiomyocytes, we examined 100,000 stimulated cells using troponin T and tropomyosin antibodies. We observed 146 adult cardiomyocytes in mitosis. All nonmitotic adult cardiomyocytes had a striated sarcomeric structure with distinct Z-discs (Fig. 7, control) that was maintained during prophase $(n=68)$. During prometaphase, however, adult cardiomyocytes lost Z-discs (Fig. 7A) and all cells in metaphase and anaphase $(n=78)$ showed absent Z-discs. In addition, a mesh of tropomyosin was formed around the chromosomes. In metaphase, this mesh became a ring. In telophase, sarcomeric striations began to be restored (Fig. 7B). Thus, mitosis in adult cardiomyocytes is associated with transient dedifferentiation of the contractile apparatus, a pro- cess similar to that observed in proliferating fetal cardiomyocytes in vivo (Rumyantsev 1977). In addition, aurora B staining showed adult cardiomyocytes in early and late phases of cytokinesis (Fig. 7B). These findings indicate the formation of a contractile ring, cleavage furrow, and midbody in dividing cardiomyocytes. Finally, the break of the midbody resulted in two spreading daughter cells containing an aurora B-positive remnant. These data suggest that proliferating adult cardiomyocytes dedifferentiate and then divide into new functional cardiomyocytes with differentiated sarcomeres.

\section{Role of p38 in cardiomyocyte proliferation}

Our microarray and proliferation data demonstrated that p38 inhibition promotes induction of DNA synthesis and G2/M transition in cardiomyocytes. However, inhibition of p38 alone had little or no effect on DNA synthesis or mitosis, suggesting that p38 and growth factors 
Engel et al.

Figure 6. Adult cardiomyocyte proliferation is controlled by $\mathrm{p} 38$. Adult rat cardiomyocytes were analyzed using BrdU, H3P, and aurora B. (A) p38 inhibition increased growth-factor-induced DNA synthesis (BrdU) in adult cardiomyocytes $(n=3$, mean $\pm S D$, $p<0.01)$. (B) Mitotic activity $(\mathrm{H} 3 \mathrm{P})$ in adult cardiomyocytes was increased by p38 inhibition $(n=4, \quad$ mean $\pm S D$, $p<0.01)$. (C) Adult cardiomyocytes undergo cytokinesis (aurora B) when incubated with growth factors and p38i $(n=4$, mean \pm SD, $p<0.01)$. (D) Adult cardiomyocytes undergoing mitosis (tropomyosin, red; H3P, green; DAPI, blue). $(E, F)$ Dividing adult cardiomyocytes stained for aurora B (green) and Nkx2.5 or troponin T (red). Arrows point to daughter nuclei. $(G, H)$ Binucleated adult cardiomyocytes can undergo cytokinesis. Note that the binucleated cardiomyocyte in $G$ is dividing into two mononucleated and one binucleated cell (arrows point at cleavage furrows), whereas the cardiomyocyte in $H$ is dividing into two binucleated cells.
A

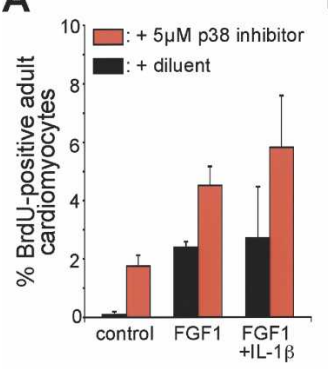

B

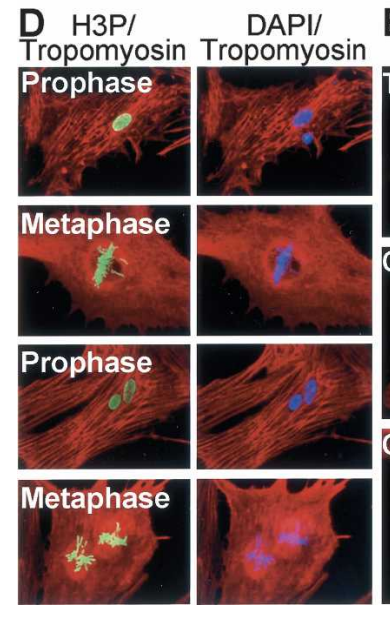

C
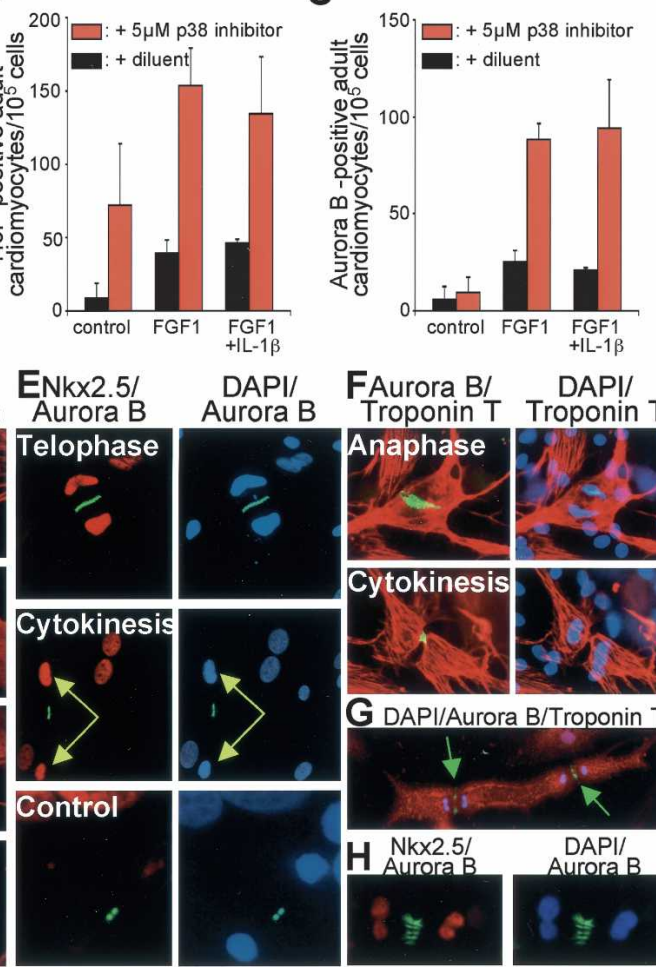

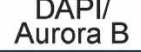

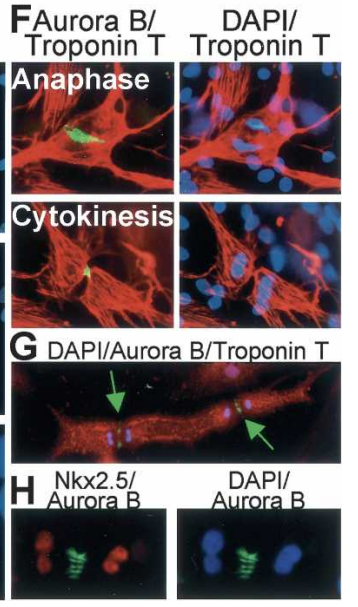

act sequentially to control progression through the different cell cycle phases. The fact that p38 inhibition can promote induction of DNA synthesis suggested that $\mathrm{p} 38$ and growth factors also act synergistically to control cardiomyocyte proliferation. To find a molecular explanation for this synergy, we re-examined our cDNA microarray data. We discovered that p38 inhibition downregulated Seta/Ruk (Fig. 1B), an adaptor protein that binds and inhibits PI3 kinase (Gout et al. 2000). Moreover, we found that Akt, a downstream target of PI3 kinase, is significantly phosphorylated in $p 38 \alpha$ knockout mice (Fig. 8A). To determine if PI3 kinase is required for FGF1 signaling in cardiomyocytes, we used the specific PI3 kinase inhibitor LY294002 (10 $\mu M)$ (Vlahos et al. 1994). LY294002 abolished FGF1-induced DNA synthesis (Fig. $8 \mathrm{~B}, \mathrm{C}$ ), suggesting that this process may require PI3 kinase activity. Thus, p38 inhibition may act synergistically with growth factors by down-regulating antagonists of PI3 kinase.

\section{Discussion}

We conclude that adult mammalian ventricular cardiomyocytes can divide. One important mechanism used by mammalian cardiomyocytes to control proliferation is p38 MAP kinase activity. Several lines of evidence support these conclusions. First, p38 regulates expression of genes required for mitosis in cardiomyocytes. Second, p38 activity is inversely correlated with cardiac growth during development, and its overexpression blocks proliferation of fetal cardiomyocytes. Third, activation of p38 in vivo by MKK3bE reduces BrdU incorporation in fetal cardiomyocytes. Fourth, p38 k knockout increased cardiomyocyte mitoses in neonatal mice. Furthermore, inhibition of p38 in cultures of adult cardiomyocytes promotes cytokinesis. Finally, mitosis is associated with transient dedifferentiation of the contractile apparatus. Thus, our data indicate that p38 is a key negative regulator of cardiomyocyte proliferation and that postmitotic cells can divide.

Our work indicates that adult mammalian cardiomyocytes can be induced to divide. Many studies have suggested that adult mammalian cardiomyocytes may possess the ability to proliferate, but these suggestions are controversial. Mitotic figures inside muscle fibers bordering necrotic myocardium were described as early as 1888 (Rumyantsev 1977). These findings have been confirmed by other researchers (Rumyantsev 1977; Anversa et al. 1991; Anversa and Kajstura 1998; Beltrami et al. 2001). However, it is not clear that these mitotic figures are in cardiomyocytes and the conclusions have been questioned (Soonpaa and Field 1998; Mummery 2005; Pasumarthi et al. 2005). Transgenic overexpression of oncogenes or cell cycle promoters has led to cardiomyocyte proliferation in adult animals (Sen et al. 1988; Jackson et al. 1990; Katz et al. 1992; Soonpaa et al. 1997; Chaudhry et al. 2004; Pasumarthi et al. 2005). In all cases, however, transgene expression began in fetal development when cardiomyocytes normally proliferate. In these studies it is possible that cardiomyocyte differentiation was altered by the transgene. Experiments trying to confirm the effect of these genes on proliferation 

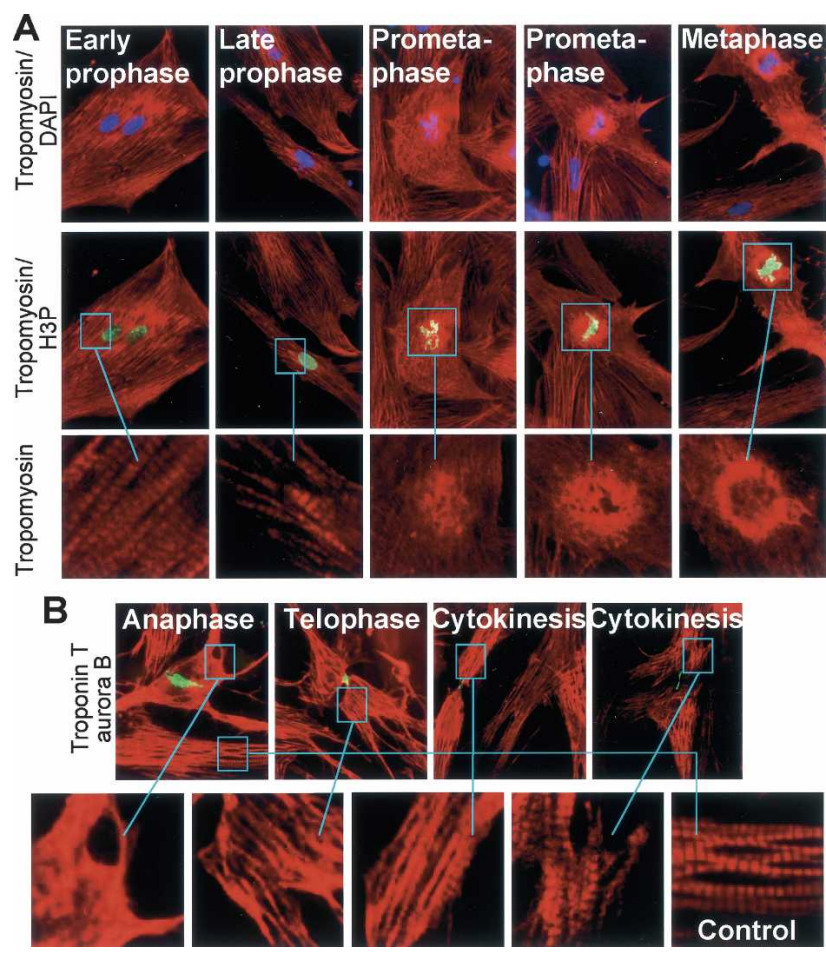

Figure 7. Transient dedifferentiation of myofibrils in proliferating adult cardiomyocytes. The extent of sarcomere differentiation was assessed in proliferating adult cardiomyocytes using tropomyosin and troponin T. (A) Adult cardiomyocytes undergoing mitosis. Cells were stained for H3P (green), tropomyosin (red), and DAPI (blue). Striations formed by Z-discs were apparent during prophase but disappeared by prometaphase. Note that a tropomyosin ring surrounding the chromosomes was formed during metaphase. $(B)$ Adult cardiomyocytes undergoing cytokinesis. Cells were stained for aurora B (green), troponin T (red), and DAPI (blue). Striations reformed during late telophase.

in wild-type adult cardiomyocytes indicated that the adult cardiomyocytes could not proliferate. For example, de novo expression of c-myc in adult myocardium in vivo using an inducible system (Xiao et al. 2001) or viral expression of cyclin D1 (Tamamori-Adachi et al. 2003) failed to induce cardiomyocyte cytokinesis. Likewise, overexpression of c-myc as well as serum stimulation in vitro did not result in adult cardiomyocyte division (Claycomb and Bradshaw 1983; Xiao et al. 2001). Here, we have demonstrated that cardiomyocytes isolated from 3-mo-old rats can be induced to divide in vitro. The advantage of this approach is that the identity of cardiomyocytes and the presence of cytokinesis can be clearly demonstrated using light microscopy and immunofluorescence staining. Several proteins induced cardiomyocyte proliferation, and we saw the greatest response with FGF1 coupled with p38 inhibitor.

Approximately $7.2 \%$ of adult cardiomyocytes re-entered the cell cycle as measured by Ki67 staining. We do not know if these cells represent a distinct cell population of adult cardiomyocytes, but we have no evidence to support this idea. All analyzed cells were positive for Nkx2.5, tropomyosin, and troponin $\mathrm{T}$ and had typical morphology of adult cardiomyocytes. None had the appearance of stem cells or fetal cardiomyocytes. The simplest interpretation of our data, therefore, is that adult cardiomyocytes can divide.

We did not document proliferation of adult cardiomyocytes in vivo. In p38 $\alpha$ knockout hearts, BrdU incorporation was increased 20 -fold, indicating that DNA synthesis in adult cardiomyocytes is enabled by the absence of p38. We did not detect H3P- or aurora B-positive adult cardiomyocytes in vivo, but this was not surprising. Our in vitro experiments showed that p38 inhibition by itself was not sufficient to induce cardiomyocyte mitosis or cytokinesis. Specific growth factors, not present in the healthy adult heart, are also required. It would be of interest in future studies to complete the characterization of the p38 $\alpha$ knockout mice and to determine if p38 inhibition enables adult cardiomyocyte proliferation in models of cardiac injury when many growth promoters are released (Lembo et al. 1995; Colucci 1997; Iwakura et al. 2000).

It is not clear how p38 inhibition enables cardiomyocyte proliferation. Previous studies have shown that p38 activation inhibits $\mathrm{S}$ phase, $\mathrm{M}$ phase, and cytokinesis in many cells by modulating cell cycle proteins like p21, cyclin D, cdc25B, cyclin B, and cdc2 (Ambrosino and Nebreda 2001; Bulavin et al. 2002; Shi and Gaestel 2002). p38 is required for differentiation of several cell types, including skeletal myoblasts and hepatocytes (Awad et al. 2000; Nebreda and Porras 2000; Wu et al. 2000). p38 promotes stabilization and enhanced translation of mRNAs, increases protein stability by phosphorylation, and is involved in chromatin remodeling (Kyriakis and Avruch 2001; Clark et al. 2003; Simone et al. 2004). Our microarray data and immunofluorescence studies show up-regulation of cdc2, cdc25B, cyclin D, and cyclin B, all factors required for cell cycle progression. It is likely therefore that p38 regulates cardiomyocyte proliferation by modulating important cell cycle factors. Our work suggests a model for regulation of cardiomyocyte proliferation (Fig. 9). FGF1 up-regulated fetal cardiac genes, inducing dedifferentiation. This process was independent of p38. In contrast, p38 inhibition promoted FGF1induced DNA synthesis (S phase). FGF1 regulated genes involved in apoptosis, and this effect was also enhanced by p38 inhibition. Finally, p38 activity prevented upregulation of factors required for karyokinesis and cytokinesis, confirming a role for p38 in G2/M checkpoint control. In addition, when p38 inhibitor was removed from culture media after induction of DNA synthesis, cardiomyocytes failed to progress through G2/M and cytokinesis (data not shown). Thus, p38 inhibition is required for growth-factor-mediated induction of all phases of the cell cycle and substantially enhances the proliferative capacity of mammalian cardiomyocytes.

Our findings have implications for the treatment of cardiac diseases. Although significant advances have been made in the management of acute myocardial infarction, ischaemic heart disease is still the leading cause of death. Recent studies reported improved cardiac function using various stem cell populations in animal mod- 
Engel et al.

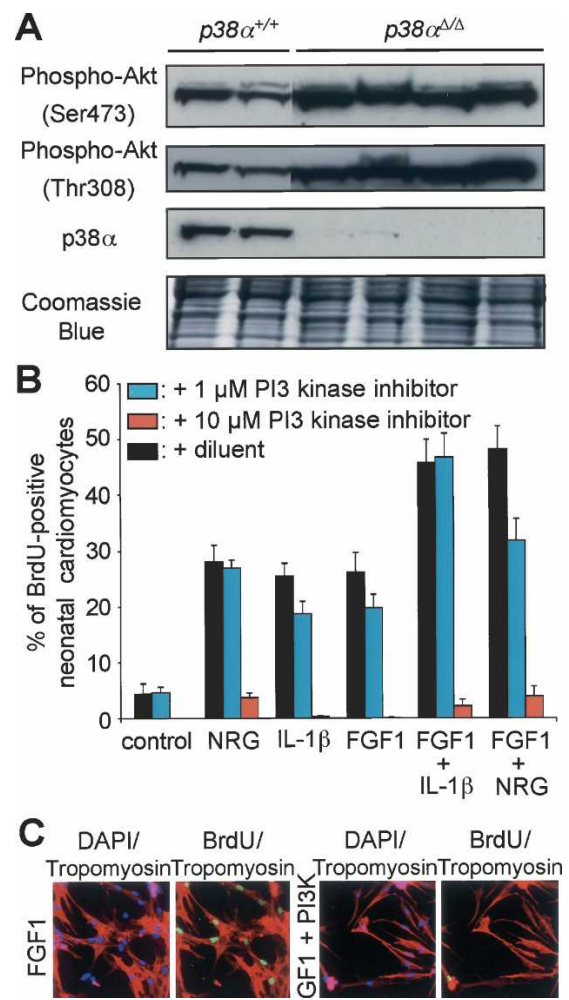

Figure 8. Potential role of PI3 kinase-Akt pathway in cardiomyocyte proliferation. PI3K activation in p38 $\alpha$ knockout hearts at basal condition. (A) PI3 kinase activity was determined from the phosphorylation status of downstream substrate Akt using both anti-phospho-Ser473-Akt and anti-phospho-Thr308-Akt antibodies from wild-type $\left(p 38 \alpha^{+/+}\right)$and conditional knockout $\left(p 38 \alpha^{\Delta / \Delta}\right)$ hearts. The status of p38 $\alpha$ inactivation was confirmed by immunoblot for total p38 $\alpha$. Equal loading of the samples was demonstrated by Coomassie staining pattern of the gel as indicated. (B) Inhibition of PI3 kinase blocks neonatal cardiomyocyte proliferation potential. Neonatal rat cardiomyocytes were stimulated with FGF1, IL-1 $\beta$, and/or NRG-1- $\beta$ in the absence or presence of LY294002, and analyzed for DNA synthesis (BrdU). Inhibition of PI3 kinase by LY294002 (10 $\mu \mathrm{M})$ abolished growthfactor-induced DNA synthesis. The diluent for LY294002 was DMSO. $(C)$ Examples of cardiomyocytes stained for tropomyosin (red), BrdU (green), and DAPI (blue) used for quantitative analyses in $B$.

els of myocardial injury, but this work is controversial (Pearson 2004). Our studies suggest an alternative approach-cardiac regeneration through cardiomyocyte proliferation. This approach is appealing because mammalian heart growth during fetal development is mediated by cardiomyocyte proliferation and not through stem cells. This concept resembles liver regeneration that is based on the proliferation of differentiated hepatocytes. Similar to the heart, the majority of hepatocytes are tetraploid and previous studies have shown that diploid, tetraploid, and octoploid hepatocytes have similar capacities to proliferate (Weglarz et al. 2000). Interestingly, liver regeneration is inversely correlated with p38 activity (Awad et al. 2000). In addition, EGR-1-deficient mice exhibiting impaired liver regeneration are charac- terized by increased p38 activity and inhibition of mitotic progression (Liao et al. 2004). Furthermore, we recently demonstrated that cardiac regeneration in zebrafish is achieved through cardiomyocyte proliferation. The mitotic index in this study was $<0.5 \%$ in the wound area (Poss et al. 2002). Our results show a similar mitotic index $(0.14 \%)$ for adult mammalian cardiomyocytes. Thus, this study suggests that mammalian cardiac regeneration might be possible. Due to the extraordinary clinical importance of heart disease, it will be critical to learn in future studies if transgenic or pharmacologic p38 inhibition can be used to induce growth-factor-mediated mammalian cardiac regeneration.

\section{Materials and methods}

\section{Animals, cells, and stimulation}

Animal experiments were performed in accordance with guidelines of Children's Hospital in Boston, and Univerity of California, Los Angeles. Ventricular cardiomyocytes from fetal (E19), 2-d-old (P2), and adult (250-350 g) Wistar rats (Charles River) were isolated as described with minor modifications (Engel et al. 1999, 2003). After digestion of fetal or neonatal hearts $(0.14$ $\mathrm{mg} / \mathrm{mL}$ collagenase II [Invitrogen], $0.55 \mathrm{mg} / \mathrm{mL}$ pancreatin [Sigma]), cells were cultured in DMEM/F12 (GIBCO) containing $3 \mathrm{mM}$ Na-pyruvate, $0.2 \%$ BSA, $0.1 \mathrm{mM}$ ascorbic acid (Sigma), $0.5 \%$ Insulin-Transferrin-Selenium $(100 \times)$, penicillin $(100 \mathrm{U} / \mathrm{mL})$, streptomycin $(100 \mu \mathrm{g} / \mathrm{mL})$, and $2 \mathrm{mM}$ L-glutamine (GIBCO). Adult cardiomyocytes were cultured for $1 \mathrm{~d}$ in standard medium (DMEM, $25 \mathrm{mM}$ HEPES, $5 \mathrm{mM}$ taurine, $5 \mathrm{mM}$ creatine, $2 \mathrm{mM}$ L-carnitine [Sigma], $20 \mathrm{U} / \mathrm{mL}$ insulin [GIBCO], 0.2\% BSA, penicillin $[100 \mathrm{U} / \mathrm{mL}]$, and streptomycin $[100 \mu \mathrm{g} / \mathrm{mL}])$. Cells were stimulated in culture medium without BSA containing $2 \mathrm{mM}$ L-glutamine. Neonatal and adult cardiomyocytes were initially cultured for $48 \mathrm{~h}$ in the presence of $20 \mu \mathrm{M}$ cytosine $\beta$-D-arabinofuranoside ( $\mathrm{araC}$; Sigma) and 5\% horse serum before stimulation to prevent proliferation of nonmyocytes. Adult cardiomyocytes were incubated another $3 \mathrm{~d}$ with araC during stimulation. Neonatal cardiomyocytes were stimulated every day with growth factors for BrdU and $\mathrm{H} 3 \mathrm{P}$ analyses (FGF1 and NRG- $1-1 \beta$ at $50 \mathrm{ng} / \mathrm{mL}, \mathrm{IL}-1 \beta$ at $100 \mathrm{ng} / \mathrm{mL}$ R $\& D$ Systems; all diluted in $0.1 \%$ BSA/PBS). SB203580 and LY294002 (Calbiochem) were added every day. Adult cardiomyocytes were stimulated with fresh medium and SB203580 every $3 \mathrm{~d}$.

\section{Transgenic animals}

The $M K K 3 b E$ transgenic animals were reported previously (Liao et al. 2001).

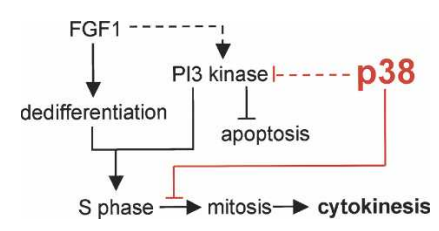

Figure 9. Model for cardiomyocyte proliferation. p38 inhibits the transition from $\mathrm{S}$ phase to mitosis by down-regulating mitotic genes. p38 inhibition acts synergistically with FGF1 to promote cell cycle progression, possibly through molecules like PI3 kinase. 
The $p 38 \alpha$ floxed allele was generated by homologous recombination in embryonic stem cells (Lexicon) in which the first exon (containing ATG) was flanked by two loxP sites. See Supplemental Material for details. The floxed allele was bred into homozygosity and genotyped using Southern blot and PCR analysis. The conditional knockout was generated by crossing $M L C-2 a / C r e$ with homozygous floxed $p 38 \alpha$ mice. The $M L C-2 a /$ Cre mice contain CRE coding sequence knocked into the $M L C$ $2 a$ allele. All transgenic animals were maintained in a C57Black background. Only male animals were used for adult studies.

\section{In vivo BrdU labeling}

Pregnant $M K K 3 b E$ (E21) and newborn $p 38 \alpha$ knockout mice (P3) were injected i.p. with $10 \mathrm{~mL} / \mathrm{kg}$ body weight of $\mathrm{BrdU}$ (10 mM in saline) and sacrificed $18 \mathrm{~h}$ later. Adult mice (10 wk) were injected with BrdU solution $96 \mathrm{~h}$ and $48 \mathrm{~h}$ before tissue collection. Neonatal hearts were fixed in ice-cold $10 \%$ buffered formalin, incubated in $30 \%$ sucrose (both overnight at $4^{\circ} \mathrm{C}$ ), embedded in tissue-freezing medium (Fisher), stored for $24 \mathrm{~h}$ at $-20^{\circ} \mathrm{C}$, and sectioned (10 $\mu \mathrm{m}$; Leica $\left.3050 \mathrm{~S}\right)$. Adult hearts were embedded in tissue-freezing medium (Fisher) without fixation.

\section{Heart growth}

Images of hearts were analyzed with NIH Image 1.62 software to determine the maximal area (ma). Heart growth was calculated as $\left(\mathrm{ma}_{\mathrm{Ex}} / \mathrm{ma}_{\mathrm{Ex}-1}\right) \times 100-100$, where Ex is the specific embryonic day.

\section{Immunofluorescence staining}

Staining was performed as described (Supplementary Table S3; Engel et al. 1999, 2003). Immune complexes were detected with ALEXA 350-, ALEXA 488-, or ALEXA 594-conjugated secondary antibodies (1:200; Molecular Probes). DNA was visualized with DAPI (4',6'-diamidino-2-phenylindole, $0.5 \mu \mathrm{g} / \mathrm{mL}$; Sigma). For $\mathrm{BrdU}$, cells were cultured in $30 \mu \mathrm{M}$ BrdU, incubated after permeabilization for $90 \mathrm{~min}$ in $2 \mathrm{~N} \mathrm{HCl} / 1 \%$ Triton $\mathrm{X}-100$, and washed three times in PBS.

\section{p38 kinase assay and Western blotting}

p38 kinase activity was determined with the p38 MAP Kinase Assay kit (Cell Signaling). Hearts were homogenized in lysis buffer (10x tissue volume) containing $1 \mathrm{mM}$ Pefabloc SC (Roche), sonicated, and centrifuged. Anti-phospho-p38 immunoprecipitates for kinase reactions were derived from $200 \mu \mathrm{g}$ of protein. Extracts containing $20 \mu \mathrm{g}$ of protein or $20 \mu \mathrm{L}$ of kinase reaction were resolved by NuPAGE Novex Bis-Tris Gels (Invitrogen) and detected as described (Supplementary Table S3). Signals were quantified by NIH Image 1.62 software.

\section{Electroporation and adenoviral infection}

Plasmids to overexpress $\mathrm{p} 38 \alpha$ and $\mathrm{p} 38 \alpha \mathrm{DN}$ (Raingeaud et al. 1995) were electroporated into fetal cardiomyocytes according to the manufacturer's instructions (Amaxa). The transfection efficiency of cardiomyocyte cultures was $>30 \%$ (Gresch et al. 2004). Neonatal cardiomyocyte cultures were infected with adenoviral constructs Ad-p38 $\alpha \mathrm{DN}$, Ad-p38ßDN (Wang et al. 1998), and Ad-GFP (Clontech) after preplating. Infection efficiency of cardiomyocyte cultures was $>90 \%$ as determined by indirect immunofluorescence.

\section{Proliferation assay}

Cells were trypsinized and washed in ice-cold PBS, and cell number was determined with a hemocytometer. The percentage of cardiomyocytes was determined as described (Engel et al. 1999).

\section{Microarray analysis and $R T-P C R$}

RNA of neonatal cardiomyocytes was prepared $72 \mathrm{~h}$ after stimulation using Trizol (Invitrogen). RT-PCR was performed following standard protocols (Supplementary Table S4). Affymetrix technology was applied using the Rat Expression Set 230.

\section{Statistical analysis}

Eighteen to 40 hearts of three different litters were used for quantitative analyses of maximal areas. For immunofluorescence analyses, 1500 fetal or neonatal cardiomyocytes were counted. For adult cardiomyocyte analyses in vitro, the following numbers of cells were counted: $500-2000$ for BrdU or Ki67, 9000-25,000 for H3P, and 12,000-45,000 for aurora B. For in vivo $M K K 3 b E$ and $p 38 \alpha$ knockout experiments, two different litters were used. We counted 1500-2000 cells in each apex, left and right ventricle per heart. For adult experiments, we analyzed two $p 38 \alpha^{\Delta / \Delta}$ and two $p 38^{\text {lox/lox }}$ hearts (24 sections each). Statistical significance was determined using a Student's $t$-test.

\section{Acknowledgments}

We thank R. Davis for p38 expression constructs; S. Izumo for Nkx2.5 antibodies; J. Han for p38 $\beta$ and p38 $\gamma$ antibodies; Dr. Ju Chen for cre mice; Haiying Pu, Mary L. McFarland, and Lynn Pantages-Torok for their technical assistance; D. Clapham for confocal imaging equipment; W. Earnshaw and K. Stringer for advice on cytokinesis detection; S. Elledge, L. Cantley, J. Blenis, D. Clapham, R. King, M. Kirschner, C-L. Lien, S. Makino, and I. Splawski for critique of the manuscript; and Keating laboratory members for helpful discussions.

\section{References}

Ambrosino, C. and Nebreda, A.R. 2001. Cell cycle regulation by p38 MAP kinases. Biol. Cell 93: 47-51.

Anversa, P. and Kajstura, J. 1998. Ventricular myocytes are not terminally differentiated in the adult mammalian heart. Circ. Res. 83: 1-14.

Anversa, P., Fitzpatrick, D., Argani, S., and Capasso, J.M. 1991. Myocyte mitotic division in the aging mammalian rat heart. Circ. Res. 69: 1159-1164.

Awad, M.M., Enslen, H., Boylan, J.M., Davis, R.J., and Gruppuso, P.A. 2000. Growth regulation via p38 mitogenactivated protein kinase in developing liver. J. Biol. Chem. 275: 38716-38721.

Azmi, S., Sun, H., Ozog, A., and Taneja, R. 2003. mSharp-1/ DEC2, a basic helix-loop-helix protein functions as a transcriptional repressor of E box activity and Stra13 expression. J. Biol. Chem. 278: 20098-20109.

Bao, Z.Z., Bruneau, B.G., Seidman, J.G., Seidman, C.E., and Cepko, C.L. 1999. Regulation of chamber-specific gene expression in the developing heart by Irx4. Science 283: 11611164.

Beltrami, A.P., Urbanek, K., Kajstura, J., Yan, S.M., Finato, N., Bussani, R., Nadal-Ginard, B., Silvestri, F., Leri, A., Beltrami, C.A., et al. 2001. Evidence that human cardiac myocytes 
Engel et al.

divide after myocardial infarction. N. Engl. I. Med. 344: 1750-1757.

Brockes, J.P. and Kumar, A. 2002. Plasticity and reprogramming of differentiated cells in amphibian regeneration. Nat. Rev. Mol. Cell Biol. 3: 566-574.

Brodsky, V.Y. 1991. Cell ploidy in the mammalian heart. Harwood Academic Publishers, New York.

Brown, D.C. and Gatter, K.C. 2002 . Ki67 protein: The immaculate deception? Histopathology 40: 2-11.

Bulavin, D.V., Amundson, S.A., and Fornace, A.J. 2002. p38 and Chk1 kinases: Different conductors for the G2/M checkpoint symphony. Curr. Opin. Genet. Dev. 12: 92-97.

Cameron, V.A. and Ellmers, L.J. 2003. Minireview: Natriuretic peptides during development of the fetal heart and circulation. Endocrinology 144: 2191-2194.

Chaudhry, H.W., Dashoush, N.H., Tang, H., Zhang, L., Wang, X., Wu, E.X., and Wolgemuth, D.J. 2004. Cyclin A2 mediates cardiomyocyte mitosis in the postmitotic myocardium. J. Biol. Chem. 279: 35858-35866.

Chotteau-Lelievre, A., Desbiens, X., Pelczar, H., Defossez, P.A., and de Launoit, Y. 1997. Differential expression patterns of the PEA3 group transcription factors through murine embryonic development. Oncogene 15: 937-952.

Clark, A.R., Dean, J.L., and Saklatvala, J. 2003. Post-transcriptional regulation of gene expression by mitogen-activated protein kinase p38. FEBS Lett. 546: 37-44.

Classon, M. and Harlow, E. 2002. The retinoblastoma tumour suppressor in development and cancer. Nat. Rev. Cancer 2: 910-917.

Claycomb, W.C. and Bradshaw Jr., H.D. 1983. Acquisition of multiple nuclei and the activity of DNA polymerase $\alpha$ and reinitiation of DNA replication in terminally differentiated adult cardiac muscle cells in culture. Dev. Biol. 99: 331-337.

Colucci, W.S. 1997. Molecular and cellular mechanisms of myocardial failure. Am. J. Cardiol. 80: 15L-25L.

Engel, F.B., Hauck, L., Cardoso, M.C., Leonhardt, H., Dietz, R., and von Harsdorf, R. 1999. A mammalian myocardial cellfree system to study cell cycle reentry in terminally differentiated cardiomyocytes. Circ. Res. 85: 294-301.

Engel, F.B., Hauck, L., Boehm, M., Nabel, E.G., Dietz, R., and von Harsdorf, R. 2003. p21(CIP1) controls proliferating cell nuclear antigen level in adult cardiomyocytes. Mol. Cell. Biol. 23: 555-565.

Enslen, H., Raingeaud, J., and Davis, R.J. 1998. Selective activation of p38 mitogen-activated protein (MAP) kinase isoforms by the MAP kinase kinases MKK3 and MKK6. J. Biol. Chem. 273: 1741-1748.

Eriksson, M. and Leppa, S. 2002. Mitogen-activated protein kinases and activator protein 1 are required for proliferation and cardiomyocyte differentiation of P19 embryonal carcinoma cells. J. Biol. Chem. 277: 15992-16001.

Gout, I., Middleton, G., Adu, J., Ninkina, N.N., Drobot, L.B., Filonenko, V., Matsuka, G., Davies, A.M., Waterfield, M., and Buchman, V.L. 2000. Negative regulation of PI 3-kinase by Ruk, a novel adaptor protein. EMBO J. 19: 4015-4025.

Gresch, O., Engel, F.B., Nesic, D., Tran, T.T., England, H.M., Hickman, E.S., Korner, I., Gan, L., Chen, S., Castro-Obregon, S., et al. 2004. New non-viral method for gene transfer into primary cells. Methods 33: 151-163.

Iiizumi, M., Arakawa, H., Mori, T., Ando, A., and Nakamura, Y. 2002. Isolation of a novel gene, CABC1, encoding a mitochondrial protein that is highly homologous to Yyast activity of bc1 complex. Cancer Res. 62: 1246-1250.

Iwakura, A., Fujita, M., Ikemoto, M., Hasegawa, K., Nohara, R., Sasayama, S., Miyamoto, S., Yamazato, A., Tambara, K., and Komeda, M. 2000. Myocardial ischemia enhances the ex- pression of acidic fibroblast growth factor in human pericardial fluid. Heart Vessels 15: 112-116.

Jackson, T., Allard, M.F., Sreenan, C.M., Doss, L.K., Bishop, S.P., and Swain, J.L. 1990. The c-myc proto-oncogene regulates cardiac development in transgenic mice. Mol. Cell. Biol. 10: 3709-3716.

Katz, E.B., Steinhelper, M.E., Delcarpio, J.B., Daud, A.I., Claycomb, W.C., and Field, L.J. 1992. Cardiomyocyte proliferation in mice expressing $\alpha$-cardiac myosin heavy chain-SV40 T-antigen transgenes. Am. J. Physiol. 262: H1867-H1876.

Kitsberg, D., Formstecher, E., Fauquet, M., Kubes, M., Cordier, J., Canton, B., Pan, G., Rolli, M., Glowinski, J., and Chneiweiss, H. 1999. Knock-out of the neural death effector domain protein PEA-15 demonstrates that its expression protects astrocytes from $\mathrm{TNF} \alpha$-induced apoptosis. J. Neurosci. 19: 8244-8251.

Kyriakis, J.M. and Avruch, J. 2001. Mammalian mitogen-activated protein kinase signal transduction pathways activated by stress and inflammation. Physiol. Rev. 81: 807-869.

Lembo, G., Hunter, J.J., and Chien, K.R. 1995. Signaling pathways for cardiac growth and hypertrophy. Recent advances and prospects for growth factor therapy. Ann. NY Acad. Sci. 752: $115-127$.

Liang, Q. and Molkentin, J.D. 2003. Redefining the roles of p38 and JNK signaling in cardiac hypertrophy: Dichotomy between cultured myocytes and animal models. J. Mol. Cell Cardiol. 35: 1385-1394.

Liao, P., Georgakopoulos, D., Kovacs, A., Zheng, M., Lerner, D., $\mathrm{Pu}$, H., Saffitz, J., Chien, K., Xiao, R.P., Kass, D.A., et al. 2001. The in vivo role of $\mathrm{p} 38$ MAP kinases in cardiac remodeling and restrictive cardiomyopathy. Proc. Natl. Acad. Sci. 98: $12283-12288$.

Liao, Y., Shikapwashya, O.N., Shteyer, E., Dieckgraefe, B.K., Hruz, P.W., and Rudnick, D.A. 2004. Delayed hepatocellular mitotic progression and impaired liver regeneration in early growth response-1-deficient mice. J. Biol. Chem. 279: 43107-43116.

Lombardo, F., Komatsu, D., and Hadjiargyrou, M. 2004. Molecular cloning and characterization of Mustang, a novel nuclear protein expressed during skeletal development and regeneration. FASEB J. 18: 52-61.

Mummery, C.L. 2005. Cardiology: Solace for the brokenhearted? Nature 433: 585-587.

Murray, A.W. 2004. Recycling the cell cycle: Cyclins revisited. Cell 116: 221-234.

Nebreda, A.R. and Porras, A. 2000. p38 MAP kinases: Beyond the stress response. Trends Biochem. Sci. 25: 257-260.

Parker, T.G., Packer, S.E., and Schneider, M.D. 1990. Peptide growth factors can provoke "fetal" contractile protein gene expression in rat cardiac myocytes. J. Clin. Invest. 85: 507514.

Pasumarthi, K.B. and Field, L.J. 2002. Cardiomyocyte cell cycle regulation. Circ. Res. 90: 1044-1054.

Pasumarthi, K.B.S., Nakajima, H., Nakajima, H.O., Soonpaa, M.H., and Field, L.J. 2005. Targeted expression of cyclin D2 results in cardiomyocyte DNA synthesis and infarct regression in transgenic mice. Circ. Res. 96: 110-118.

Pearson, H. 2004. The heart of the matter. Nat. Med. 10: 445446.

Poss, K.D., Wilson, L.G., and Keating, M.T. 2002. Heart regeneration in zebrafish. Science 298: 2188-2190.

Poss, K.D., Keating, M.T., and Nechiporuk, A. 2003. Tales of regeneration in zebrafish. Dev. Dyn. 226: 202-210.

Raingeaud, J., Gupta, S., Rogers, J.S., Dickens, M., Han, J., Ulevitch, R.J., and Davis, R.J. 1995. Pro-inflammatory cytokines and environmental stress cause p38 mitogen-activated 
protein kinase activation by dual phosphorylation on tyrosine and threonine. J. Biol. Chem. 270: 7420-7426.

Rumyantsev, P.P. 1977. Interrelations of the proliferation and differentiation processes during cardiac myogenesis and regeneration. Int. Rev. Cytol. 51: 186-273.

Saito, S., Liu, X.F., Kamijo, K., Raziuddin, R., Tatsumoto, T., Okamoto, I., Chen, X., Lee, C.C., Lorenzi, M.V., Ohara, N., et al. 2004. Deregulation and mislocalization of the cytokinesis regulator ECT2 activate the Rho signaling pathways leading to malignant transformation. J. Biol. Chem. 279: 7169-7179.

Sen, A., Dunnmon, P., Henderson, S.A., Gerard, R.D., and Chien, K.R. 1988. Terminally differentiated neonatal rat myocardial cells proliferate and maintain specific differentiated functions following expression of SV40 large T antigen. J. Biol. Chem. 263: 19132-19136.

Shi, Y. and Gaestel, M. 2002. In the cellular garden of forking paths: How p38 MAPKs signal for downstream assistance. Biol. Chem. 383: 1519-1536.

Simone, C., Forcales, S.V., Hill, D.A., Imbalzano, A.N., Latella, L., and Puri, P.L. 2004. p38 pathway targets SWI-SNF chromatin-remodeling complex to muscle-specific loci. Nat. Genet. 36: 738-743.

Soonpaa, M.H. and Field, L.J. 1998. Survey of studies examining mammalian cardiomyocyte DNA synthesis. Circ. Res. 83: $15-26$.

Soonpaa, M.H., Koh, G.Y., Pajak, L., Jing, S., Wang, H., Franklin, M.T., Kim, K.K., and Field, L.J. 1997. Cyclin D1 overexpression promotes cardiomyocyte DNA synthesis and multinucleation in transgenic mice. J. Clin. Invest. 99: 2644-2654.

Studzinski, G.P. and Harrison, L.E. 1999. Differentiation-related changes in the cell cycle traverse. Int. Rev. Cytol. 189: $1-58$

Tamamori-Adachi, M., Ito, H., Sumrejkanchanakij, P., Adachi, S., Hiroe, M., Shimizu, M., Kawauchi, J., Sunamori, M., Marumo, F., Kitajima, S., et al. 2003. Critical role of cyclin D1 nuclear import in cardiomyocyte proliferation. Circ. Res. 92: e12-e19.

Vlahos, C.J., Matter, W.F., Hui, K.Y., and Brown, R.F. 1994. A specific inhibitor of phosphatidylinositol 3-kinase, 2-(4-morpholinyl)-8-phenyl-4H-1-benzopyran-4-one (LY294002). I. Biol. Chem. 269: 5241-5248.

Wang, X.S., Diener, K., Manthey, C.L., Wang, S., Rosenzweig, B., Bray, J., Delaney, J., Cole, C.N., Chan-Hui, P.Y., Mantlo, N., et al. 1997. Molecular cloning and characterization of a novel p38 mitogen-activated protein kinase. J. Biol. Chem. 272: 23668-23674.

Wang, Y., Huang, S., Sah, V.P., Ross Jr., J., Brown, J.H., Han, J., and Chien, K.R. 1998. Cardiac muscle cell hypertrophy and apoptosis induced by distinct members of the p38 mitogenactivated protein kinase family. J. Biol. Chem. 273: 21612168.

Weglarz, T.C., Degen, J.L., and Sandgren, E.P. 2000. Hepatocyte transplantation into diseased mouse liver. Kinetics of parenchymal repopulation and identification of the proliferative capacity of tetraploid and octaploid hepatocytes. Am. I. Pathol. 157: 1963-1974.

Weiskirchen, R., Pino, J.D., Macalma, T., Bister, K., and Beckerle, M.C. 1995. The cysteine-rich protein family of highly related LIM domain proteins. I. Biol. Chem. 270: 2894628954.

Wheatley, S.P., Carvalho, A., Vagnarelli, P., and Earnshaw, W.C. 2001. INCENP is required for proper targeting of Survivin to the centromeres and the anaphase spindle during mitosis. Curr. Biol. 11: 886-890.
Wu, Z., Woodring, P.J., Bhakta, K.S., Tamura, K., Wen, F., Feramisco, J.R., Karin, M., Wang, J.Y., and Puri, P.L. 2000. p38 and extracellular signal-regulated kinases regulate the myogenic program at multiple steps. Mol. Cell. Biol. 20: 39513964.

Xiao, G., Mao, S., Baumgarten, G., Serrano, J., Jordan, M.C., Roos, K.P., Fishbein, M.C., and MacLellan, W.R. 2001. Inducible activation of $\mathrm{c}-\mathrm{Myc}$ in adult myocardium in vivo provokes cardiac myocyte hypertrophy and reactivation of DNA synthesis. Circ. Res. 89: 1122-1129.

Yoshizumi, M., Lee, W.S., Hsieh, C.M., Tsai, J.C., Li, J., Perrella, M.A., Patterson, C., Endege, W.O., Schlegel, R., and Lee, M.E. 1995. Disappearance of cyclin A correlates with permanent withdrawal of cardiomyocytes from the cell cycle in human and rat hearts. I. Clin. Invest. 95: 2275-2280. 


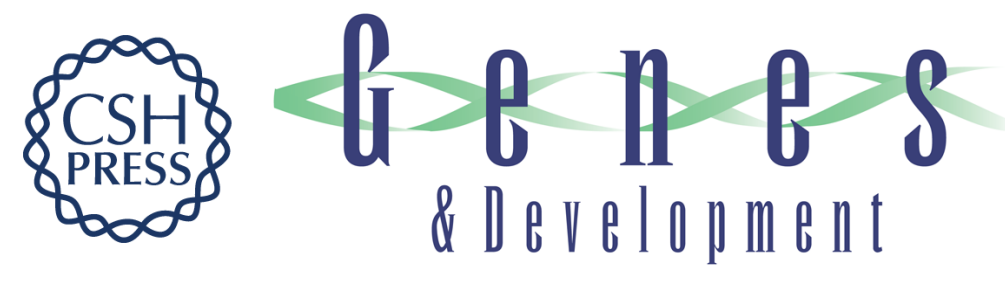

\section{p38 MAP kinase inhibition enables proliferation of adult mammalian cardiomyocytes}

Felix B. Engel, Michael Schebesta, Mychelle T. Duong, et al.

Genes Dev. 2005, 19:

Access the most recent version at doi:10.1101/gad.1306705

\section{Supplemental http://genesdev.cshlp.org/content/suppl/2005/05/04/gad.1306705.DC1 Material}

References This article cites 59 articles, 30 of which can be accessed free at: http://genesdev.cshlp.org/content/19/10/1175.full.html\#ref-list-1

\section{License}

Email Alerting

Receive free email alerts when new articles cite this article - sign up in the box at the top Service 